\title{
Mathematics Magazine
}

\section{HM-LM-AM Inequalities}

\section{Ángel Plaza}

To cite this article: Ángel Plaza (2021) HM-LM-AM Inequalities, Mathematics Magazine, 94:2, 148-148, DOI: 10.1080/0025570X.2021.1867451

To link to this article: https://doi.org/10.1080/0025570X.2021.1867451

$$
\text { 册 Published online: } 08 \text { Apr } 2021 .
$$

Submit your article to this journal $\square$

$$
\text { Џ Article views: } 250
$$

Q View related articles $₫$

View Crossmark data $\nearrow$ 


\title{
PROOFS WITHOUT WORDS
}

\section{HM-LM-AM Inequalities}

\author{
ÁNGEL PLAZA \\ Universidad de Las Palmas de Gran Canaria, Spain \\ angel.plaza@ulpgc.es
}

Let $a, b \in \mathbb{R}$, with $a \neq b$. The harmonic, logarithmic, and arithmetic means of $a$ and $b$ are respectively defined by $H(a, b)=\frac{2}{\frac{1}{a}+\frac{1}{b}}=\frac{2 a b}{a+b}, L(a, b)=\frac{b-a}{\ln b-\ln a}$, and $A(a, b)=\frac{a+b}{2}$.

Theorem. For $0<a<b, \frac{2}{a+b}<\frac{\ln b-\ln a}{b-a}<\frac{a+b}{2 a b}$, which may be written as $(A M)^{-1}<(L M)^{-1}<(H M)^{-1}$.

Proof. Let us consider functions $2 /(a+b), 1 / x$, and the linear interpolation between points $(a, 1 / a)$ and $(b, 1 / b)$.

$$
\frac{1}{a}+\frac{1}{b}=\frac{a+b}{2 a b}
$$

For $x \in(0,(b-a) / 2), \frac{1}{a+x}+\frac{1}{b-x} \geq \frac{4}{a+b}$ by the AM-HM inequality.

Then, by the mean value theorem for definite integrals there exists $c \in$ $(a,(a+b) / 2)$ such that $\frac{1}{c}=\frac{\ln b-\ln a}{b-a}$.

Summary. We demonstrate visually the inequalities among the harmonic mean, the logarithmic mean and the arithmetic mean of two positive numbers.

ÁNGEL PLAZA (MR Author ID: 350023, ORCID: 0000-0002-5077-6531) received his master's degree from Universidad Complutense de Madrid in 1984 and his Ph.D. from Universidad de Las Palmas de Gran Canaria in 1993, where he is a Full Professor in Applied Mathematics.

Math. Mag. 94 (2021) 148. doi:10.1080/0025570x.2021.1867451 (C) Mathematical Association of America MSC: Primary 97H30, Secondary 11B39 